\title{
Rancang Bangun Aplikasi Pendaftaran Pasien dan Rekam Medis Berbasis Web pada Apotik Tri Arga Farma Kota Sorong
}

\author{
Rendra Soekarta*1, Teguh Hidayat Iskandar Alam², Nunung Malik \\ 1,2,3Program Studi Teknik Informatika, Universitas Muhammadiyah Sorong \\ e-mail: *11 rendrasoekarta@gmail.com, ${ }^{2}$ teguhhidayat@gmail.com, ${ }^{3}$ nunungmalik@gmail.com
}

\begin{abstract}
Abstrak
Apotik Tri Arga Farma Kota Sorong membuka pelayanan dokter praktek. Apotik Tri Arga Farma menyediakan 5 dokter. Sistem yang sedang berjalan yaitu daftar nama untuk mendapatkan nomor antrian, kemudian menunggu giliran untuk konsultasi, catat rekam medis dan resep, terakhir membawa kertas resep ke bagian apoteker. Pencatatan masih dilakukan dalam buku besar. Data pasien masih di simpan dalam selembar kertas dan pada saat pasien kembali berobat data akan dicari dalam tumpukan kertas yang ada di lemari. yang menimbulkan resiko tertukarnya data, hilang, ataupun terbengkalai. Ini membuat pelayanan terhambat karena membutuhkan waktu yang lama untuk mencari data pasien. Tujuan dari penelitian ini yaitu membuat aplikasi pendaftaran pasien dan rekam medis berbasis web untuk mempermudah pasien mendaftar dan menyediakan tempat penyimpanan data pasien beserta rekam medis
\end{abstract}

Kata kunci-3-5 kata kunci, Algoritma A, algoritma B, kompleksitas

\section{PENDAHULUAN}

A potik Tri Arga Farma adalah apotik yang membuka pelayanan kesehatan praktek dokter, beralamat di Jl. Ahmad Yani No.17 Kelurahan Klakublik Kota Sorong. Dalam apotik tersebut ada 5 pelayanan praktek dokter yaitu Dr. Sunartojo, Sp.OG spesialis kandungan, Dr. Anthonius Ipsan, Sp.A spesialis anak, Dr. Edy Driyanto, Sp.PD spesialis penyakit dalam, Dr. Unggul Jatmiko, Sp.B spesialis bedah dan Dr. Novelina Damanik praktek umum.

Berdasarkan observasi, penulis mendapati sistem yang berjalan saat ini masih menggunakan sistem manual yang belum terkomputerisasi. Dalam pelayanan pendaftarannya, setiap pasien yang datang akan dicatat dalam buku yang di beri nomor dan dijadikan sebagai antrian pasien. Data dan kartu berobat dari setiap pasien pun masih dicatat di selembar kertas yang apabila pasien tersebut kembali berobat, pasien harus membawa kartu berobat tersebut. Jika pasien tidak membawa kartu berobat maka petugas yang melayani akan mencari data pasien berdasarkan tanggal lahir pada tumpukan kertas yang ada dilemari apotik akibatnya proses tersebut membuat data pasien lain terbengkalai (tercecer), proses ini pula yang membuat data tertukar dikarenakan nama pasien mirip.

Dengan demikian, waktu yang dibutuhkan akan lebih lama sehingga penanganan pasien tidak bisa cepat. Kondisi seperti ini sangat tidak memungkinkan untuk pasien yang sedang urgent. Pencatatan rekam medis yang masih manual ini juga beresiko kerusakan fisik kertas dan jumlah data akan bertambah seiring berkembangnya rekam medis pasien. Perawatan dari kertas rekam medis tersebut pun tergolong sulit. 


\section{METODE PENELITIAN}

\subsection{Metode Waterfall}

Metode waterfall atau yang sering disebut metode air terjun sering dinamakan siklus hidup klasik (classic life cycle), dimana hal ini menggambarkan pendekatan yang sistematis dan juga berurutan pada pengembangan perangkat lunak, dimulai dengan spesifikasi kebutuhan pengguna lalu berlanjut melalui tahapan-tahapan perencanaan (planning), permodelan (modeling), konstruksi (construction), serta penyerahan sistem ke para pengguna (deployment), dan diakhiri dengan dukungan pada perangkat lunak lengkap yang dihasilkan.

\subsection{Sistem Informasi}

Sistem informasi adalah kombinasi dari teknologi informasi dan aktivitas orang yang menggunakan teknologi itu untuk mendukung operasi dan manajemen. Istilah sistem informasi yang sering digunakan merujuk pada interaksi antara orang, proses algoritmik, data, dan teknologi. Dalam pengertian ini, istilah yang digunakan untuk merujuk tidak hanya pada penggunaan organisasi teknologi informasi dan komunikasi (TIK), tetapi juga untuk cara dimana orang berinteraksi dengan teknologi ini dalam mendukung bisnis.

\subsection{Analisa Data}

Analisa data adalah upaya atau cara untuk mengolah data menjadi informasi sehingga karakteristik data tersebut bisa dipahami dan bermanfaat untuk solusi permasalahan, terutama masalah yang berkaitan dengan penelitian. Berdasarkan hasil observasi dan Analisa yang penulis lakukan pada Apotik Tri Arga Farma Kota Sorong, sistem yang sedang berjalan saat ini yaitu sebagai berikut :

a. Pasien yang hendak berobat datang ke apotik untuk mendaftar (ambil nomor antrian).

b. Asisten dokter mencatat daftar pasien di buku besar.

c. Setelah mendaftar, pasien akan menunggu giliran sesuai nomor antrian dan pada saat pasien hendak masuk ke ruangan dokter, asisten dokter memberikan selembar kertas rekam medis untuk diserahkan ke dokter yang bersangkutan.

d. Kemudian pasien masuk ke ruangan dokter untuk konsultasi.

e. Setelah selesai berkonsultasi, pasien kembali ke meja asisten dokter untuk membayar biaya konsultasi/Tindakan.

f. Terakhir, memberikan resep ke apoteker untuk di tebus.

Berdasarkan masalah diatas, dapat di usulkan sebuah sistem untuk mengatur atau memperbaiki sistem yang sedang berjalan. Adapun sistemnya yaitu sebagai berikut :

Tabel 1. Sistem yang diusulkan

\begin{tabular}{|c|l|l|l|}
\hline No. & Kebutuhan & \multicolumn{1}{|c|}{ Masalah } & \multicolumn{1}{|c|}{ Usulan } \\
\hline 1 & $\begin{array}{c}\text { Pendaftaran } \\
\text { Pasien }\end{array}$ & $\begin{array}{l}\text { Pasien harus datang ke } \\
\text { apotik untuk mendaftar dan } \\
\text { mengambil nomor antrian }\end{array}$ & $\begin{array}{l}\text { Membuat aplikasi pendaftaran } \\
\text { pasien online berbasis web agar } \\
\text { dapat diakses kapanpun }\end{array}$ \\
\hline 2 & Antrian Pasien & $\begin{array}{l}\text { Pasien menunggu lama } \\
\text { untuk berobat }\end{array}$ & $\begin{array}{l}\text { Membuat form nomor antrian } \\
\text { yang sedangberjalan }\end{array}$ \\
\hline 3 & Rekam Medis & $\begin{array}{l}\text { Masih di catat dalam } \\
\text { selembar kertas dan akan } \\
\text { semakin bertambah }\end{array}$ & $\begin{array}{l}\text { Membuat form pencatatan rekam } \\
\text { medis yang terkomputerisasi }\end{array}$ \\
\hline 4 & $\begin{array}{c}\text { Penyimpanan Data } \\
\text { Rekam Medis }\end{array}$ & $\begin{array}{l}\text { Data rekam medis pasien } \\
\text { masih di simpan dalam lemari } \\
\text { tumpukan kertas. }\end{array}$ & $\begin{array}{l}\text { Membuat media penyimpanan data } \\
\text { dengan database MySQL }\end{array}$ \\
\hline
\end{tabular}




\begin{tabular}{|c|c|l|l|}
\hline 5 & Resep Dokter & $\begin{array}{l}\text { Catat pada selembar kertas } \\
\text { dan kemudian dibawa ke } \\
\text { bagian apoteker untuk di } \\
\text { tebus }\end{array}$ & $\begin{array}{l}\text { Membuat form penebusan resep } \\
\text { tanpa harus menggunakan kertas lagi }\end{array}$ \\
\hline
\end{tabular}

Untuk kebutuhan fungsionalnya, dapat di simpulkan sebagai berikut :

a. Sistem hanya dapat di akses jika user melakukan login kedalam aplikasi.

b. Sistem memiliki beberapa jenis level user yaitu admin, asisten dokter, dokter, apoteker dan pasien. Masing-masing level user akan memiliki hak akses yang berbeda pada aplikasi yang dibuat.

\subsection{Perancangan Flowchart}

Berikut flowchart yang telah dibuat oleh penulis untuk menjelaskan urutan atau proses dari prosedur yang ada.

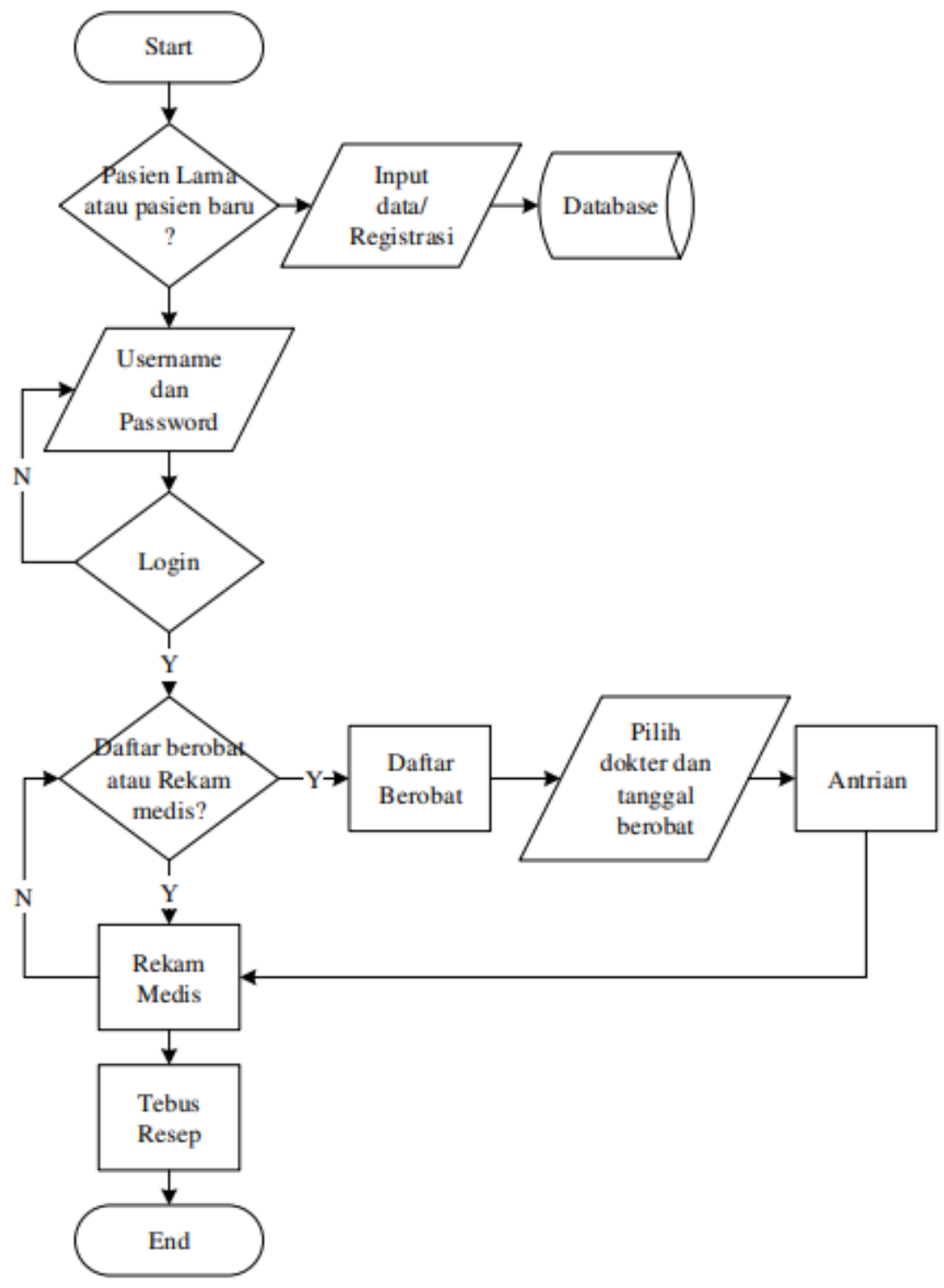

Gambar 1. Flowchart Pasien 

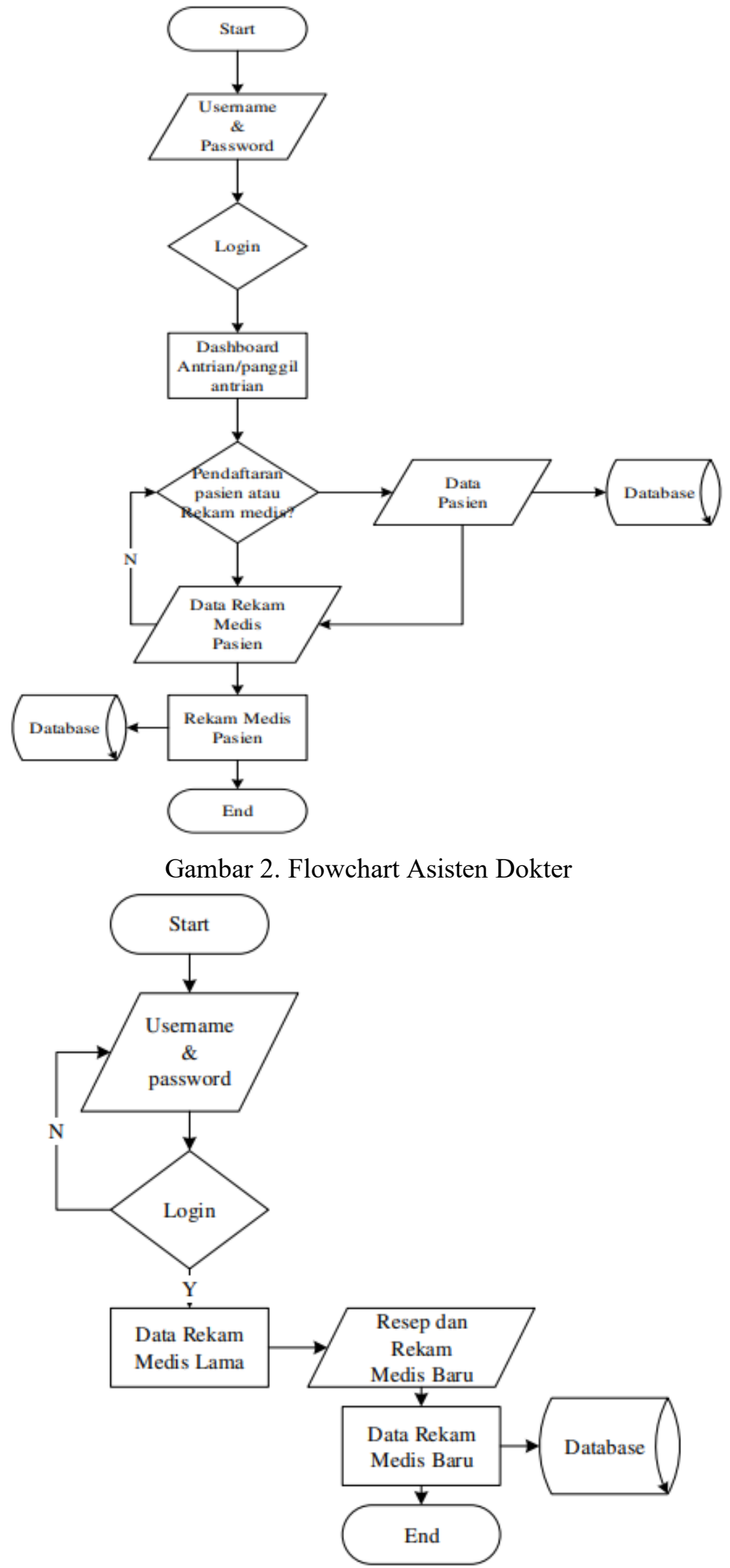

Gambar 3. Flowchart Dokter 


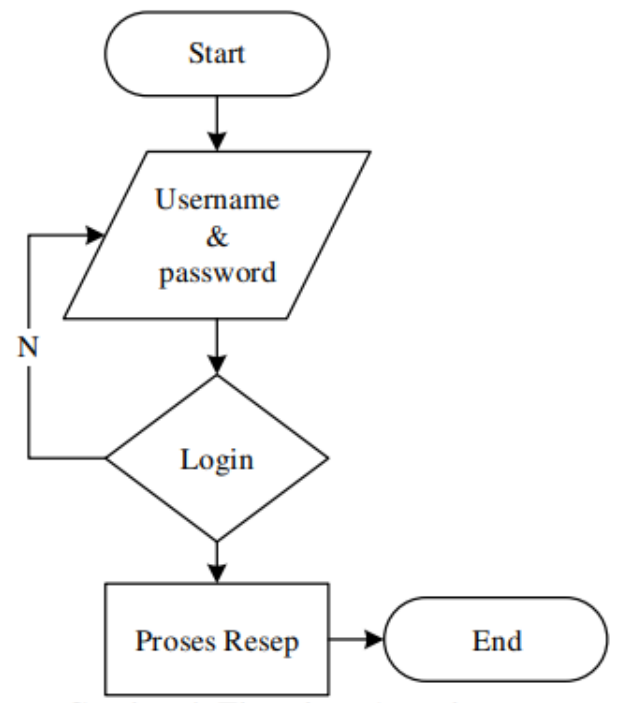

Gambar 4. Flowchart Apoteker

\subsection{Perancangan Use Case}

Use case bertujuan agar programmer lebih mudah mengidentifikasi kebutuhan sistem, dan menguraikan interaksi antara aktor dengan sistem. Berikut ilustrasinya :

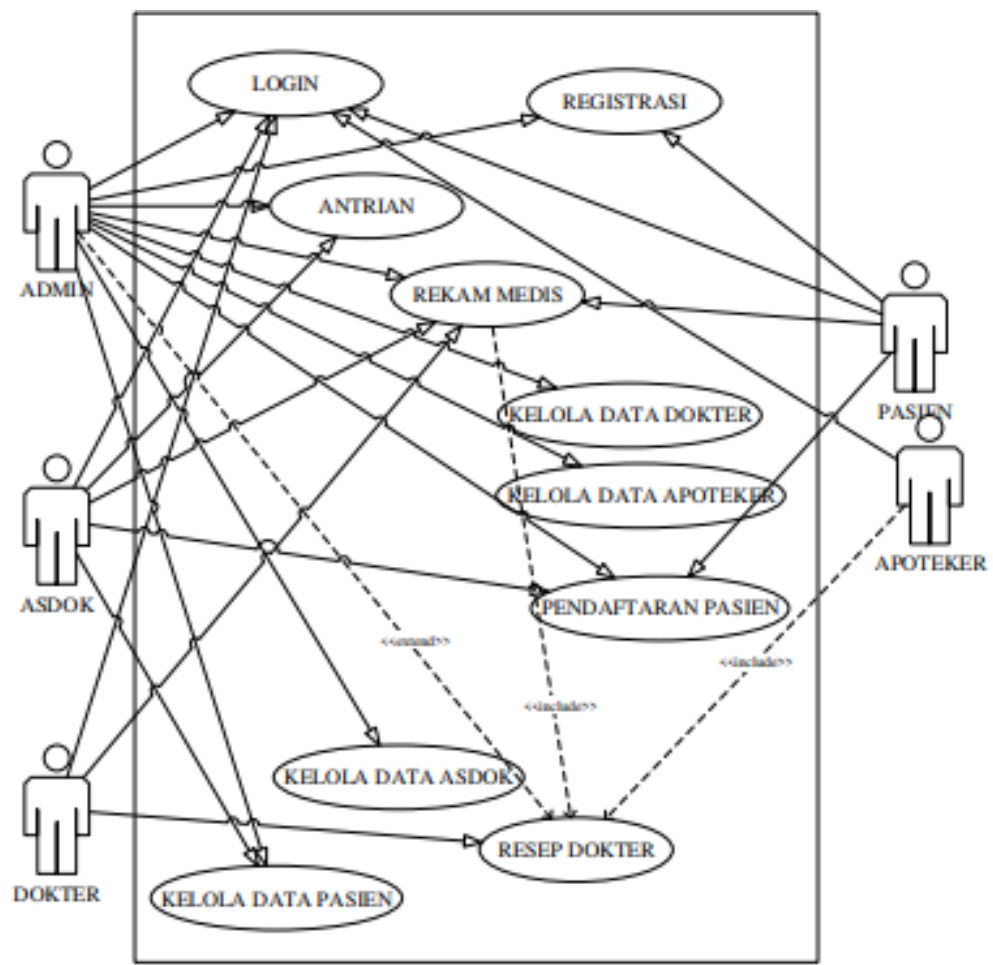

Gambar 5. Rancangan Use Case

\subsection{Perancangan ERD (Entity Relationship Diagram)}

Pembuatan ERD bertujuan untuk mendokumentasikan data-data yang ada dengan cara mengidentifikasi setiap entitas dari data-data dan hubungannya. Berikut ERD yang telah dibuat : 


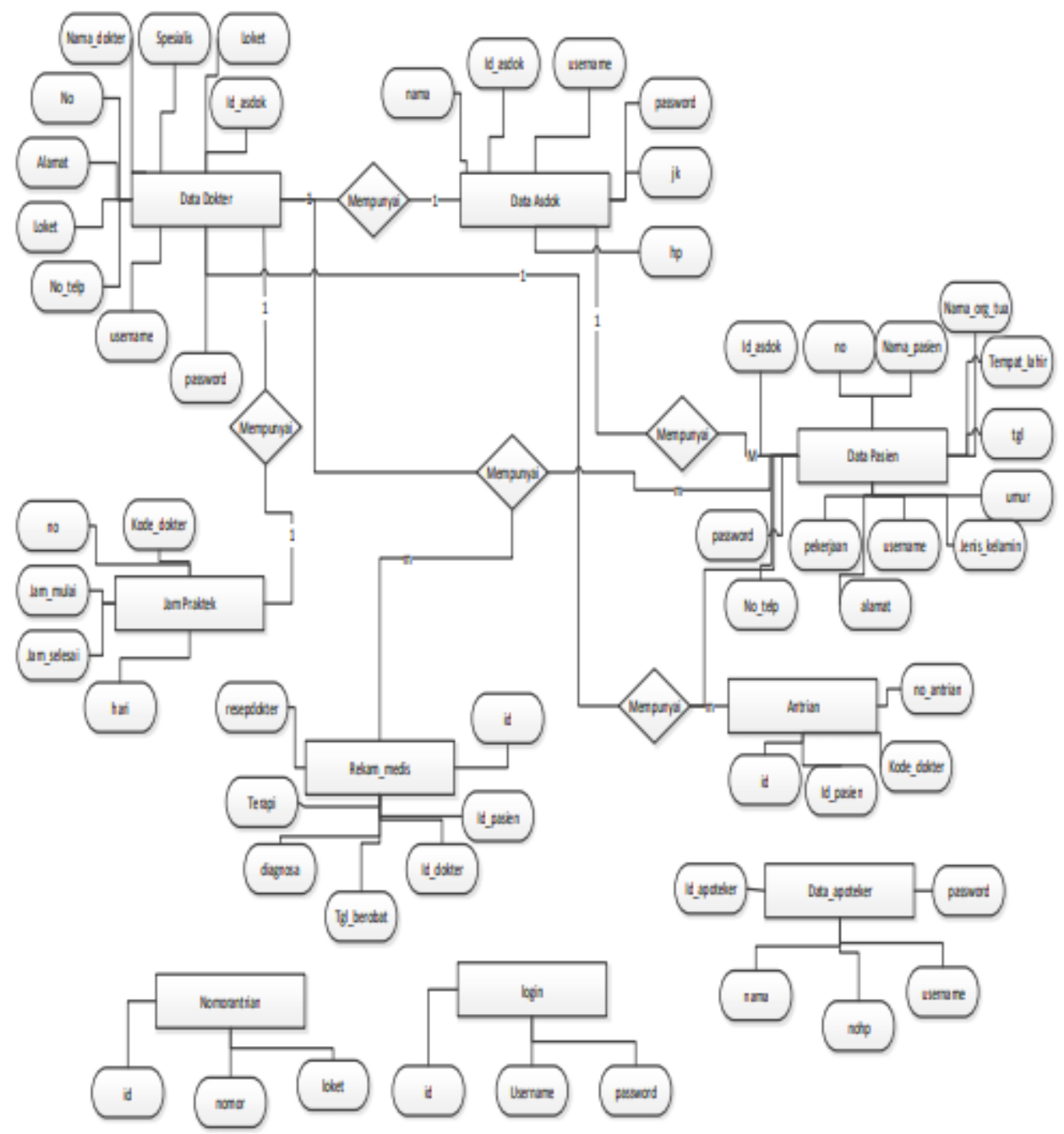

Gambar 6. Rancangan ERD

\section{HASIL DAN PEMBAHASAN}

\subsection{Implementasi}

Pada tahap ini akan dijelaskan mengenai perangkat-perangkat yang digunakan sebagai media penerapan hasil dari penelitian.

1. Perangkat Keras

- Laptop Acer intel ${ }^{\circledR}$ Celeron ${ }^{\circledR}$ processor N3350

- Memory (RAM) 2GB

- Hardisk

- Mouse

2. Perangkat Lunak

- Sistem Operasi Windows 10

- $\quad$ Sublime Text 3

- XAMPP V3.2.4 sebagai web server dan database server

- Microsoft Office Visio 2013 sebagai media perancangan system

- Web browser 


\subsection{Tampilan Menu}

Setelah membuat form rancangan desain interface, penulis mengimplementasikan form tersebut dalam aplikasi. Berikut tampilannya :

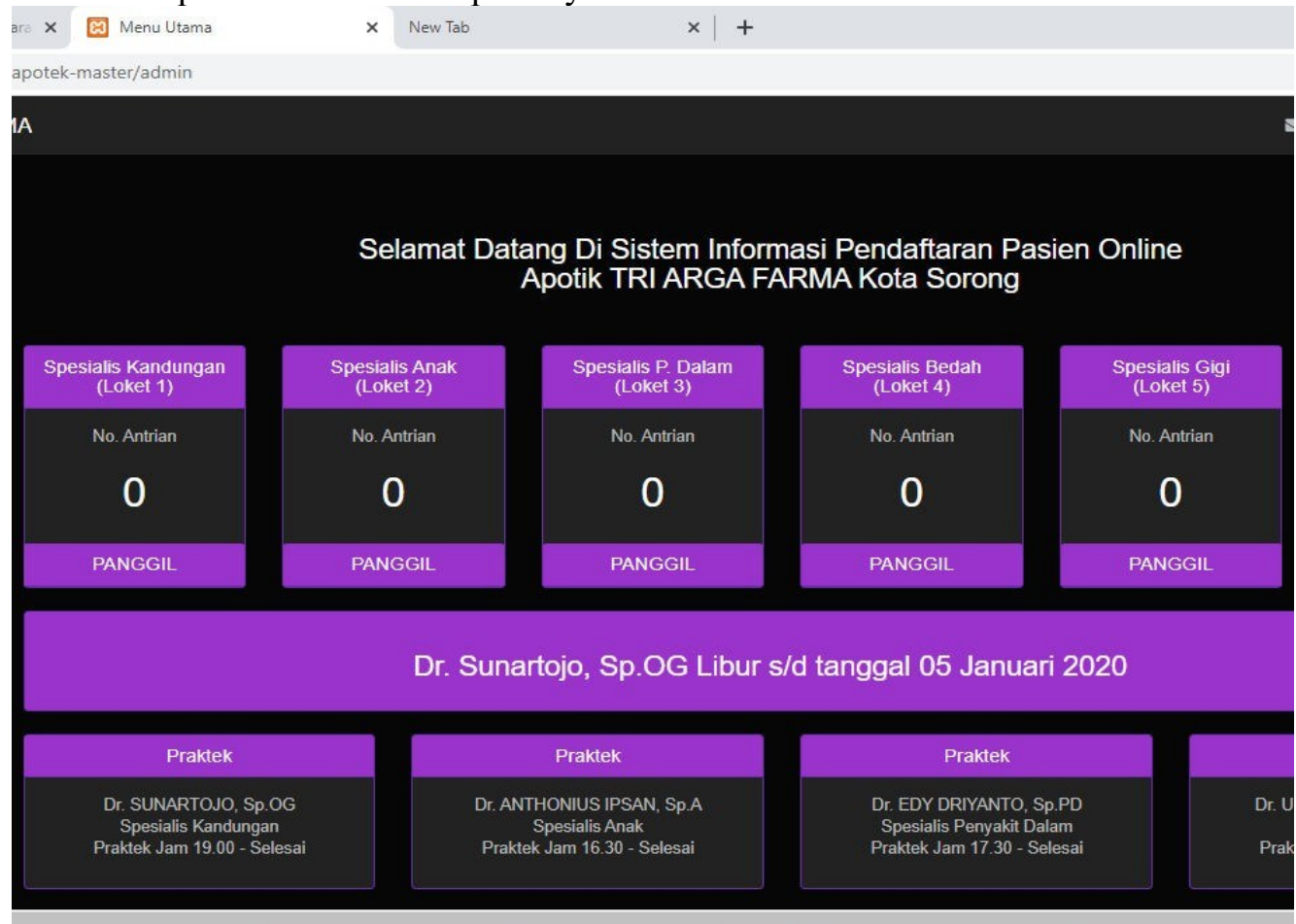

Gambar 7. Form Menu Utama

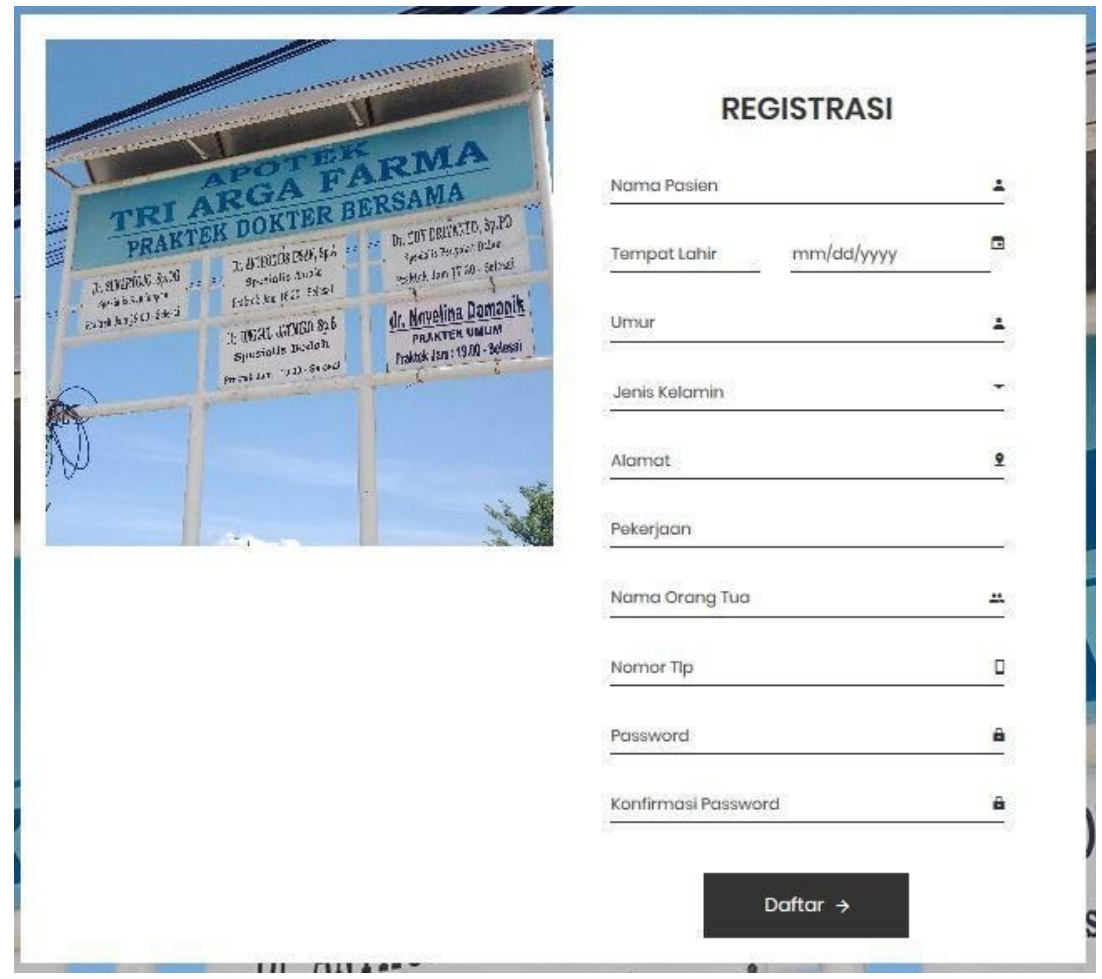

Gambar 8. Form Pendaftaran Pasien Baru 


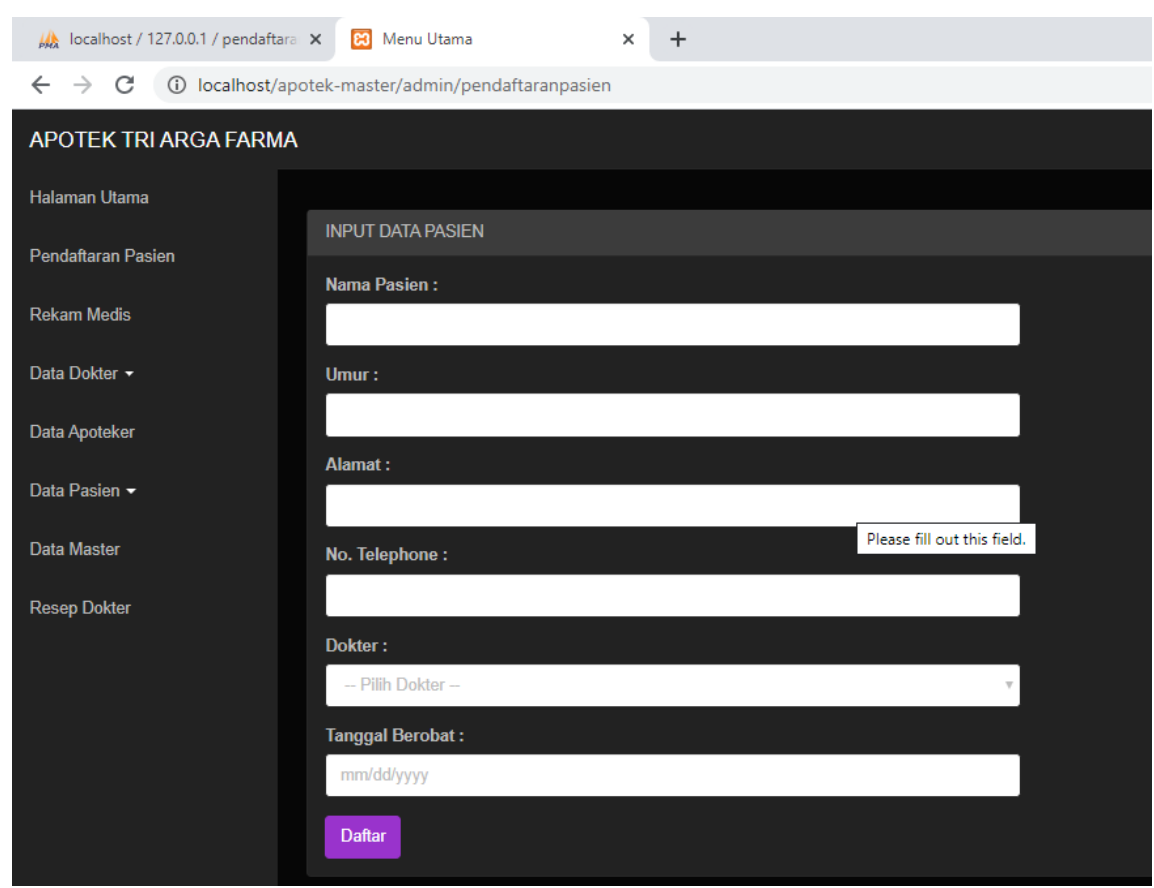

Gambar 9. Form Pendaftaran Pasien Berobat

\section{KESIMPULAN}

Berdasarkan hasil penelitian yang dilakukan penulis, ada beberapa kesimpulan yang di dapat yaitu sebagai berikut :

1. Aplikasi pendaftaran pasien dan rekam medis ini menghasilkan sebuah sistem informasi untuk mempermudah pasien maupun dokter dengan memanfaatkan teknologi yang ada saat ini.

2. Aplikasi dapat di akses melalui web browser untuk mendaftar tanpa harus datang hanya untuk mendaftar di Apotik.

3. Setiap pasien mendapatkan satu id dan bisa digunakan untuk di semua dokter dalam apotik tersebut.

\section{SARAN}

Penelitian yang telah dilakukan masih terdapat kekurangan dan masih dapat dikaji lebih lanjut lagi. Oleh sebab itu peneliti memberikan saran-saran terkait pengembangan penelitian ini yaitu:

1. Penelitian ini agar dapat dijadikan sebagai referensi untuk penelitian selanjutnya di masa mendatang.

2. Baiknya sistem di update ke sistem yang terbaru untuk mengikuti perkembangan teknologi.

3. Membangun keamanan sistem yang baik agar data yang tersimpan dalam aplikasi aman.

\section{UCAPAN TERIMA KASIH}


Alhamdulillah, puji syukur penulis panjatkan kepada Tuhan Yang Maha Esa karena berkat Rahmat dan Karunia-Nya, sehingga penulis dapat menyelesaikan penelitian ini. Terima kasih juga kepada semua pihak yang membantu sehingga penelitian ini dapat terselesaikan.

\section{DAFTAR PUSTAKA}

[1] Antonio, H., \& Safriadi, N. (2012). Rancang Bangun Sistem Informasi Administrasi Informatika (SI-ADIF). Jurnal ELKHA Vol.4, No 2.

[2] Handayani, T., \& Feoh, G. (2016). Perancangan Sistem Informasi Rekam Medis Berbasis Web (Studi Kasus di Klinik Bersalin Sriati Kota Sungai Penuh-Jambi). Jurnal Teknologi Informasi dan Komputer Vol. 2 No. 2.

[3] Handiwidjojo, W. (2015). Rekam Medis Elektronik. Program Studi Teknik Informatika Universitas Kristen Duta Wacana Yogyakarta.

[4] Indarti, \& Laraswati, D. (2018). Rancang Bangun Sistem Informasi Pelayanan Kesehatan Berbasis Web Pada Klinik Umum Galur Medika Jakarta Pusat. Jurnal Teknik Komputer Vol. 4 No. 2.

[5] Iwan Setiawan, S. M., \& Marwanto Rahmatuloh, S. M. (2019). Rancang Bangun Sistem Aplikasi Pendaftaran Badan Kependudukan Dan Keluarga Berencana Daerah (BKKBD) Online Berbasis Web Studi Kasus Di Bojonggenteng Sukabumi. Jurnal Teknik Informatika, Vol. 11, No. 1.

[6] Junaidi, Arifin, R., \& Septiani, A. (2015). Rancang Bangun Aplikasi Sistem Inventory Berbasis Desktop Menggunakan JSE . Konferensi Nasional Sistem \& Informatika 2015 STMIK STIKOM Bali, 9 - 10 Oktober 2015.

[7] Kadir, \& Abdul. (2014). Pengenalan Sistem Informasi Edisi Revisi. Yogyakarta: Andi Yogyakarta.

[8] Nugroho, B. (2019). Aplikasi Pemrograman Web Dinamis Dengan PHP dan MySQL. Yogyakarta: Gava Media.

[9] Pasaribu, J. S., \& Sihombing, J. (2017). Perancangan Sistem Informasi Rekam Medis Pasien Rawat Jalan Berbasis Web di Klinik Sehat Margasari Bandung. Jurnal Ilmiah Teknologi Informasi Terapan 3(3).

[10] Perdana, A. B., Negara, A. B., \& Irwansyah, M. A. (2016). Rancang Bangun Sistem Informasi Rekam Medis Berbasis Website (Studi Kasus: Rumah Sakit Umum Daerah Sultan Syarif Mohamad Alkadrie. Jurnal Sistem dan Teknologi Informasi 4(2). 